\title{
Underwater endoscopic mucosal resection of a laterally spreading tumor overlying a previous endoscopic carbon tattoo
}
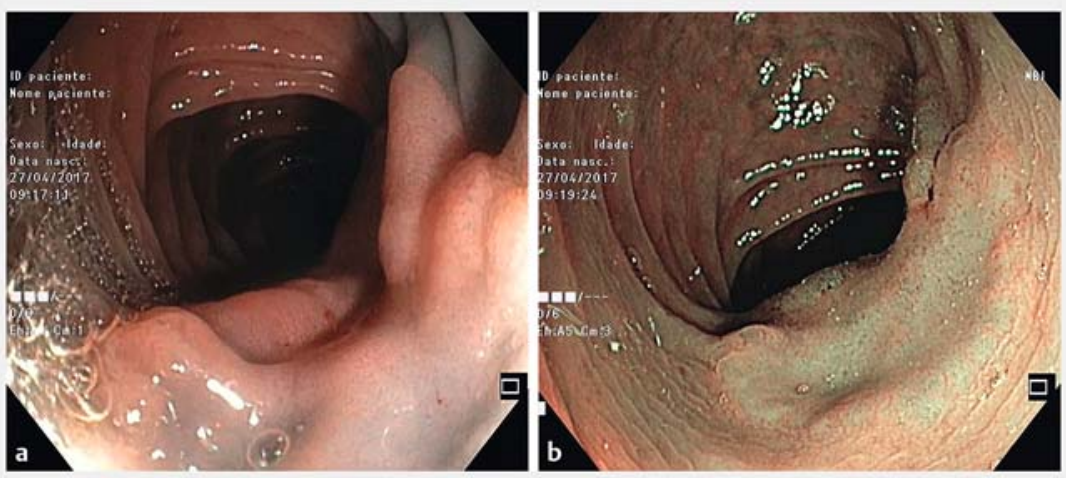

- Fig. 1 On the descending colon, a 40-mm nongranular, homogeneous, laterally spreading tumor (LST) was identified, overlying a previously placed carbon tattoo. a White-light imaging. b Narrow-band imaging.
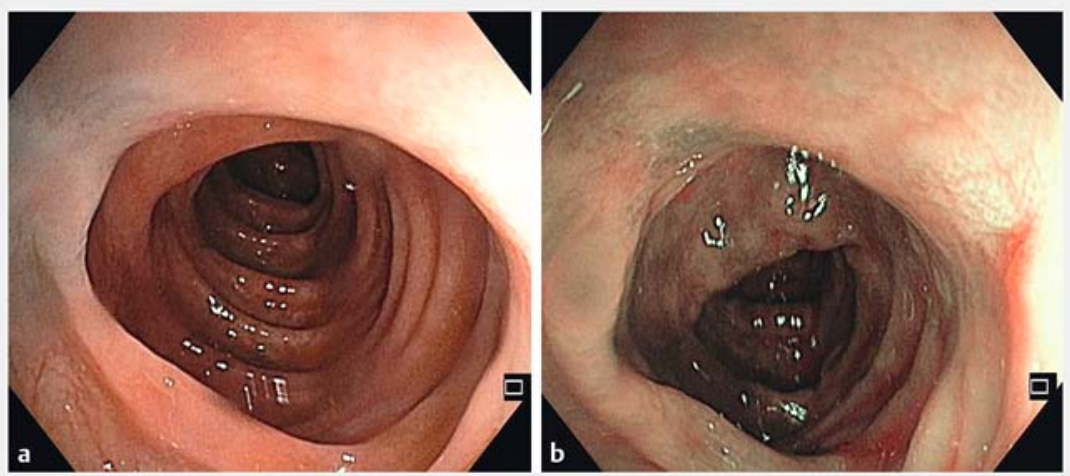

Fig. 3 Surveillance colonoscopy 3 months later showed the scar with no signs of recurrence. a White-light imaging. b Narrow-band imaging.

A 53-year-old man with no relevant past medical history was referred to our department for resection of a laterally spreading tumor (LST) on the descending colon, which had been tattooed previously.

The procedure was performed with a transparent cap attached to the tip of the colonoscope (Q185; Olympus Medical Systems, Tokyo, Japan), with the patient under deep propofol sedation. A 40-mm nongranular, homogeneous LST was identified, overlying a previously placed carbon tattoo ( $\triangleright$ Fig. $\mathbf{1}$ ), with re- sulting severe fibrosis that precluded elevation for conventional endoscopic mucosal resection (EMR). Therefore, underwater piecemeal EMR was performed, after marking the lesion limits with snare tip coagulation ( $\vee$ Video 1 ). Complete resection was achieved without complications. The procedure exposed involvement of almost all of the submucosa by the ink ( $\triangleright$ Fig.2). The patient was discharged on the same day.

Histopathological analysis revealed a tubular adenoma with low grade dysplasia, and with carbon pigment in the mar-

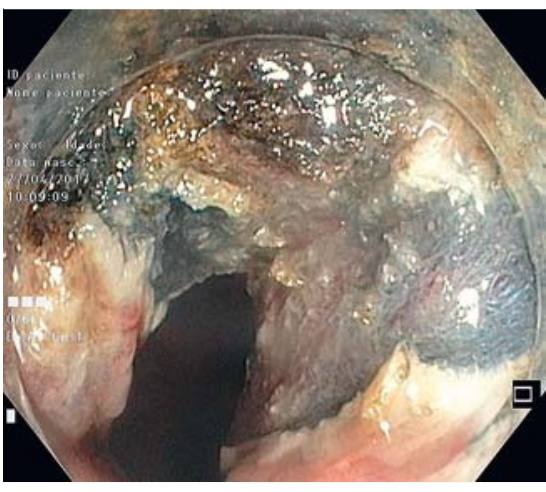

- Fig. 2 Endoscopic image showing the involvement of almost all of the submucosa beneath the scar by the carbon ink.

gins of most fragments. On surveillance colonoscopy 3 months later, the scar had no endoscopic or histological recurrence ( $>$ Fig. $\mathbf{3}$ ).

Endoscopic tattooing is a widely used technique to facilitate the identification of colorectal lesions for subsequent endoscopic or surgical treatments $[1,2]$. However, tattooing has been associated with clinically significant complications, including peritonitis [1,2]. Additionally, tattooing under a lesion can result in technical difficulties because of associated submucosal fibrosis, which makes endoscopic resection procedures hazardous and has contributed to perforation [1-3]. In fact, carbon particles can spread across a significant distance within the submucosal plane; it is therefore recommended that tattoos are placed $2-3 \mathrm{~cm}$ anatomically distal to the lesion [1,2]. Underwater EMR has been shown to be a useful technique for lesions that are difficult to resect, including those associated with fibrosis $[4,5]$. In the present report, we present the first case of a successful underwater EMR of a lesion associated with fibrosis secondary to tattoo.

Endoscopy_UCTN_Code_CPL_1AJ_2AD 


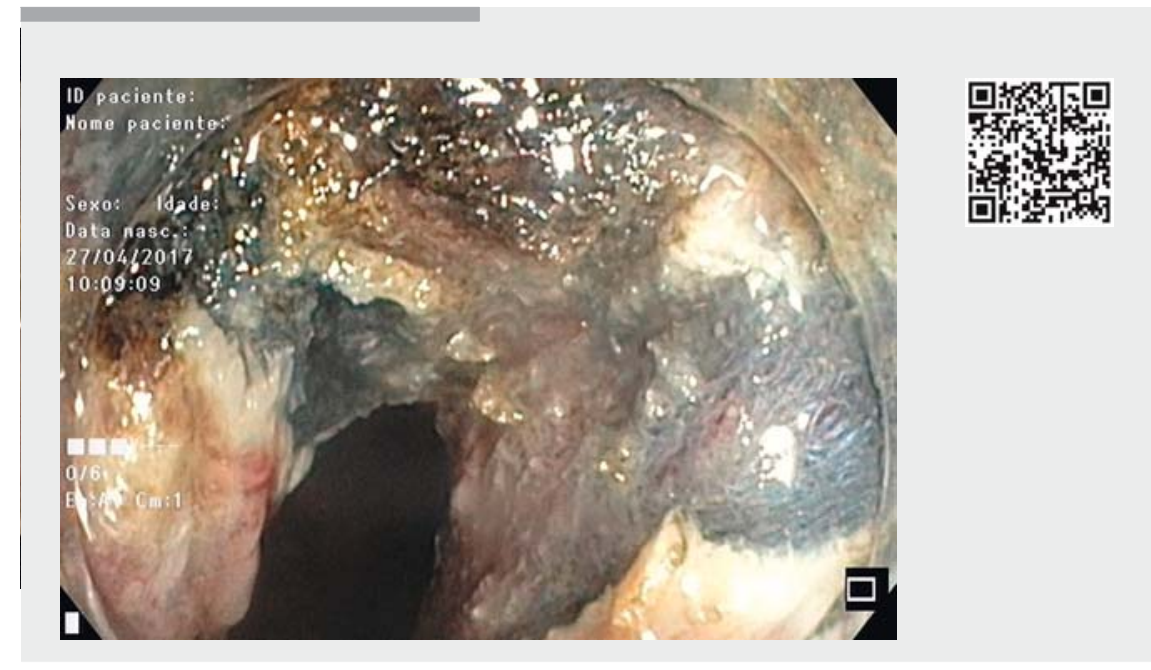

$\checkmark$ Video 1 Underwater piecemeal endoscopic mucosal resection of a laterally spreading tumor overlying a previous endoscopic carbon tattoo with associated severe fibrosis.

\section{Competing interests}

\section{None}

The authors

\section{Jaime P. Rodrigues, Rolando Pinho, Mafalda Sousa, João Carlos Silva, Catarina Gomes, João Carvalho}

Gastroenterology Department, Centro Hospitalar Vila Nova de Gaia/Espinho, Vila Nova de Gaia, Portugal

\section{Corresponding author}

\section{Jaime Pereira Rodrigues, MD}

Gastroenterology Department, Centro

Hospitalar Vila Nova de Gaia/Espinho, Rua

Conceição Fernandes, 4434-502, Vila Nova

de Gaia, Portugal

Fax: +351-227-865100

jaimepereirarodrigues@gmail.com

\section{References}

[1] Ferlitsch M, Moss A, Hassan C et al. Colorectal polypectomy and endoscopic mucosal resection (EMR): European Society of Gastrointestinal Endoscopy (ESGE) Clinical Guideline. Endoscopy 2017; 49: 270-297

[2] Moss A, Bourke M], Pathmanathan N. Safety of colonic tattoo with sterile carbon particle suspension: a proposed guideline with illustrative cases. Gastrointest Endosc 2011; 74 : $214-218$

[3] Ono S, Fujishiro M, Goto O et al. Endoscopic submucosal dissection for colonic laterally spreading tumors is difficult after target tattooing. Gastrointest Endosc (3 Pt 2) 2009; 69: $763-766$

[4] Ponte A, Pinho R, Proença L et al. Underwater endoscopic mucosal resection of a large flat adenoma with pseudoinvasion in the rectum. GE Port J Gastroenterol 2017; 24: $255-257$

[5] Kim HG, Thosani N, Banerjee S et al. Underwater endoscopic mucosal resection for recurrences after previous piecemeal resection of colorectal polyps (with video). Gastrointest Endosc 2014; 80: 1094 - 1102

\section{Bibliography}

DOI https://doi.org/10.1055/a-0624-1362

Published online: 19.6.2018

Endoscopy 2018; 50: E231-E232

(c) Georg Thieme Verlag KG

Stuttgart · New York

ISSN 0013-726X

\section{ENDOSCOPY E-VIDEOS \\ https://eref.thieme.de/e-videos}

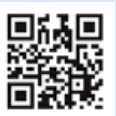

Endoscopy E-Videos is a free access online section, reporting on interesting cases and new techniques in gastroenterological endoscopy. All papers include a high quality video and all contributions are freely accessible online.

This section has its own submission website at https://mc.manuscriptcentral.com/e-videos 